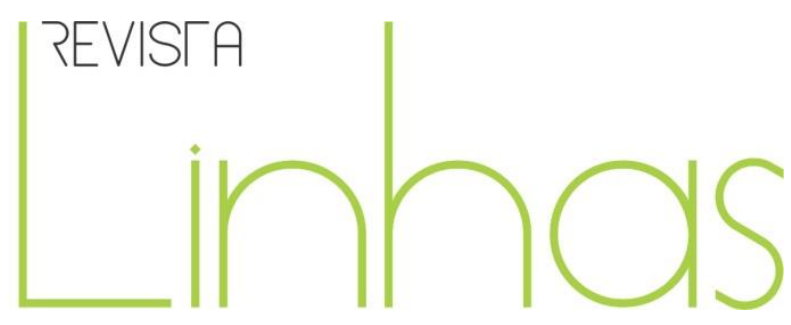

\title{
Políticas de ensino e aprendizagem de línguas estrangeiras para crianças no Brasil: (re)discutindo fundamentos
}

\begin{abstract}
Resumo
O objetivo deste artigo é buscar indícios da falta da presença de uma política de ensino-aprendizagem de língua estrangeira para crianças (LEC) nos anos iniciais do ensino fundamental do setor público, por meio de uma revisão da literatura que fundamente nossas reflexões acerca das possíveis razões que levam as autoridades educacionais a não proporem a oferta de LEC. O grande desafio que se instaura é estabelecer uma política educacional para o ensino-aprendizagem de LEC, levando em consideração, a base do neoliberalismo educativo centrado por meio das políticas públicas para o ensino fundamental. O corpus bibliográfico analisado compreende-se por teses e dissertações sobre ensino e formação de professores de LEC defendidas em Programas de Pós-Graduação de universidades públicas brasileiras. Depois de realizada a revisão de literatura, concluímos que só teremos uma política efetiva de LEC se a relação de poder (política) estiver direcionada para fins de formação humana, refutando, de modo veemente, a tendência atualmente presente no âmbito do Estado e de setores do ensino (políticas neoliberais) que consiste em reduzir a gestão escolar a soluções estritamente tecnicistas.
\end{abstract}

Palavras-chave: Política de Ensino-Aprendizagem. Crianças. Língua Estrangeira. Brasil.

\author{
Jonathas de Paula Chaguri \\ Universidade Estadual de \\ Maringá - UEM - Maringá/PR - \\ Brasil \\ jonathaschag@gmail.com \\ Juliana Reichert Assunção \\ Tonelli \\ Universidade Estadual de \\ Londrina - UEL - Londrina/PR - \\ Brasil \\ teacherjuliana@uol.com.br
}

\section{Para citar este artigo:}

CHAGURI, Jonathas de Paula; TONELLI, Juliana Reichert Assunção. Políticas de ensino e aprendizagem de línguas estrangeiras para crianças no Brasil: (re)discutindo fundamentos. Revista Linhas. Florianópolis, v. 20, n. 42, p. 281-302, jan./abr. 2019. 


\title{
Policies of foreign language teaching and learning for children in Brazil: a (re)appraisal
}

\begin{abstract}
The purpose of this article is to seek evidence of the lack of presence of a policy of foreign language teaching and learning for children (FLC) in the first years in elementary school of public school by means of bibliography review to support our reflections about the possible reasons that lead the educational authorities not to propose the provision of FLC. In this moment, the great challenge that takes place is to establish the educational policy for the teaching and learning of a FLC taking account the basis of educational neoliberalism centered in public policies for the elementary school. The bibliographical corpus analyzed consists of theses and dissertations about teaching and teacher's education of FLC defended in postgraduate program of Brazilian public universities. After the literature review was carried out, we conclude that we will only have an effective policy of FLC if the power relation (policy) is directed to human educational purposes, refuting vehement, the trend currently present within the State and educational sectors (neo-liberal policies) which consist in reducing the school management to strictly tecnicisms solutions.
\end{abstract}

Keywords: Teaching-Learning Policy. Children. Foreign Language. Brazil. 


\section{Introdução}

Pesquisadores como Almeida Filho (2001), Moita Lopes (2003), Celani (2004), Tonelli e Cristovão (2010) enfatizam a importância de se garantirem condições para que todos os indivíduos tenham acesso à aprendizagem de línguas estrangeiras, como também a necessidade de que essa condição esteja informada por uma visão que problematize as mensagens culturais e políticas, que necessariamente podem vir no processo de ensino-aprendizagem de uma língua estrangeira (doravante/LE).

Oferecer condições para que todos os indivíduos possam adquirir pelo menos uma base para desenvolvimento futuro no uso de uma LE deve ser preocupação de uma política educacional nacional. É responsabilidade das autoridades educacionais oferecerem condições adequadas para que essa base se realize (CELANI, 2000; CHAGURI, 2010a). Essas condições deverão ser levadas em conta ao se traçar uma política educacional para o ensino de LE.

Nessa perspectiva, uma política pode ser entendia como ações desencadeadas, segundo um plano e ideário, podendo ser explícita ou implicitamente concebida. Com base nesse princípio, ancorando-se nas asserções de Almeida Filho (2001), a política quando implícita, só pode ser reconhecível pela natureza dos fatos que gera e a sua desvantagem que reside na ausência de ações esperadas, na presença errática ou esporádica de ideias concretizadas. Quando explícita, uma política tem plano de desembolso, agenda e metas cobráveis pelo corpo profissional e pela sociedade.

Diante disso, centramos a nossa atenção na busca de saberes que pudessem oferecer respostas para a seguinte indagação inicial: existe uma política de ensinoaprendizagem de língua estrangeira para crianças? Nesse propósito, o objetivo maior deste texto centra-se em buscar indícios da presença ou não, de uma 'política' de ensinoaprendizagem para uma LE nos anos iniciais do ensino fundamental, correspondente ao setor público.

Com vistas a atingir o objetivo proposto, realizamos levantamento bibliográfico de artigos científicos, dissertações e teses publicados no Brasil concernentes à temática investigada ${ }^{1}$. A identificação e o registro dos trabalhos encontrados foram feitos pelos

\footnotetext{
${ }^{1}$ Trabalhos defendidos em Programas de Pós-graduação stricto sensu de Instituições de Ensino Superiores
} 
autores e pelos integrantes do grupo FELICE/CNPq em função de nossos interesses de pesquisa e do levantamento de temáticas próximas².

Assim, para conferir-Ihe um tratamento mais especializado, com uma formatação que facilite a exposição dos resultados deste estudo, o texto está dividido em cinco partes. Na primeira, esta introdução, apresenta-se um panorama geral do estudo ao leitor. Na segunda, são apresentadas algumas questões preliminares acerca da política de ensino-aprendizagem de LE. Na terceira, discutem-se os aspectos políticos que formalizam as questões políticas de LEC e argumenta-se como as políticas públicas estão envolvidas na oferta de uma LEC. Na quarta parte, evidencia-se a relação que o neoliberalismo impõe no cenário educacional, aferindo, diretamente, a política de ensinoaprendizagem de LE. Na quinta parte, por fim, apresentam-se as considerações finais, em que se apresenta uma análise final de todo o texto, e, como não poderia deixar de ser, registram-se todas as fontes utilizadas para a elaboração do artigo.

Esperamos que ao final desta discussão, torne-se clara a utilização da problemática motivadora, e a reflexão em torno da política de LEC.

\section{Questões preliminares da Língua Estrangeira para Criança}

Ao propormos uma discussão em torno dos aspectos políticos de ensinoaprendizagem de LEC, segundo Chaguri (2010a), é essencial que tenhamos claro que o ensino de LEC deva estar orientado a objetivos emancipatórios e transformadores da própria produção histórica do educando, possibilitando assim a construção de um conhecimento que o auxilie a fazer uso da língua na sociedade em que vive para seu próprio bem-estar, tornando-o capaz de lidar com os novos desafios postos em sua trajetória como sujeito formador e transformador de sua própria história.

Frente ao exposto, defendemos neste artigo que o ensino de LEC na contemporaneidade deva tentar auxiliar a criança (educando) a ser criadora e transformadora de seu próprio conhecimento e da sociedade em que vive, fortalecendo-a

(IES) públicas (estaduais e/ou federais).

${ }^{2}$ O Grupo de Pesquisa FELICE/CNPq é liderado pela segunda autora deste artigo e, para o levantamento das pesquisas recorremos ao banco de teses da CAPES bem como aos sites de universidades públicas de cada estado da federação brasileira. 
para uma visão mais acentuada das diferenças existentes no mundo, o que auxiliará na sua formação humana.

Desta forma, ao implementar o ensino de uma LEC nos anos iniciais do ensino fundamental público, a criança terá possibilidades também de agir e comunicar-se em LE nas diversas esferas cotidianas, para posteriormente, engajar-se em interações mais complexas que lhe assegurarão igualdade de oportunidades no que se diz respeito à aquisição de uma LE.

Respeitando-se tais princípios, tomamos como norte inicial a Lei de Diretrizes e Bases da Educação - LDB, Lei nº 9394/96 (BRASIL, 1996), aprovada em 20 de dezembro de 1996, que determina que o ensino nos anos iniciais do ensino fundamental tenha por finalidade o desenvolvimento do raciocínio e das atividades de expressão da criança e a sua integração no meio social e físico. A criança receberá nessa fase as técnicas fundamentais de aquisição de cultura, como a leitura, a escrita e o cálculo. Além disso, iniciará, mesmo que rudimentarmente, a identificação de suas aptidões e continuará o trabalho de socialização iniciado no jardim da infância (BRASIL, 1996). A finalidade maior, porém, é expandir o círculo de relações da criança, expandindo seu círculo afetivo para além do da família que, por vezes, pode ser estrito e se fechar sobre ela.

A escola correspondente aos anos iniciais deve estimular as possibilidades de aprendizagem da criança para posteriores estudos, e juntamente com a possibilidade de oferta de uma LE nas diversas escolas municipais da rede pública de ensino, as escolas correspondentes a essa modalidade de ensino terão seus objetivos orientados para a formação de futuros cidadãos e estudantes, como também, seus papéis mais solidificados. Assim, os objetivos das escolas que correspondem aos anos iniciais do ensino fundamental podem ser resumidos pelos Parâmetros Curriculares Nacionais - PCN do volume introdutório da seguinte forma:

1 - Compreender a cidadania como participação social e política, assim como exercício de direitos e deveres políticos civis e sociais, adotando no dia-a-dia, atitudes de solidariedade, cooperação e repúdio às injustiças. 2 - Posicionar-se de maneira crítica, responsável e construtiva nas diferentes situações sociais, utilizando o diálogo como forma de mediar, conflitos e de tornar decisões coletivas.

$[\ldots]$ 
3 - Conhecer e valorizar a pluralidade do patrimônio sociocultural brasileiro, bem como aspectos socioculturais de outros, e qualquer discriminação baseada em diferenças culturais, de classes sociais, de crianças, de sexo, de etnia ou outras características individuais e sociais. (BRASIL, 1997, p. 107)

Com a oferta de uma LE nos anos iniciais, a escola do setor público, a nosso ver, terá razões a mais que podem ser resumidas, a partir do corpus bibliográfico analisado, nas seguintes premissas: (1) apresentar a diferença cultural de nosso país confrontada à cultura, do país da língua-alvo; (2) possibilitar a compreensão dos valores e interesses por outras culturas; (3) desenvolver no aluno a capacidade de adquirir novos conhecimentos; (4) construir sua cidadania, de forma a explorar a cultura da LE, buscando novos saberes, novas ideias e uma nova visão de diferentes lugares, costumes e pessoas; (5) apreciação dos costumes e valores da outra cultura que contribuem para desenvolver a percepção da própria cultura por meio da compreensão da LE.

Sem dúvida, a aprendizagem de uma LE certamente "ajuda na constituição da auto-percepção das pessoas como seres humanos e como cidadãos" (CELANI, 2005, p. 15). Ao compreender o outro, aprendemos mais a respeito de nós mesmos e acerca de um mundo plural marcado por diferenças. A consequência natural desse processo, fortemente, será o desenvolvimento de tolerância em relação às diferenças, atributo tão importante nos embates da vida contemporânea.

Por conseguinte, para que a aprendizagem de uma LE possa estar direcionada não só a princípios instrumentais ${ }^{3}$, educacionais ${ }^{4}$ e culturais ${ }^{5}$, mas também, para a formação humana (CHAGURI, 2010a), a força desses princípios se faz sentir no estabelecimento de políticas educacionais. Por isso, nada mais pertinente do que discutirmos alguns aspectos políticos referentes ao ensino-aprendizagem de LEC, a fim de tentarmos buscar nortes que nos possibilitem indícios da problemática motivadora enunciada na introdução deste artigo.

\footnotetext{
${ }^{3}$ Compreender, falar, ler e escrever (CHAGURI, 2010a, p. 61).

${ }^{4}$ Desenvolver hábitos de reflexão, observação e formação da mentalidade (Id.).

${ }^{5}$ Refletir sobre a cultura da língua estrangeira (Id.).
} 


\section{Política educacional e o ensino-aprendizagem de Língua Estrangeira para} Criança

Como menciona Celani (2000), definir política de ensino de LE não é tarefa fácil ${ }^{6}$, pois envolve inúmeras questões e exige a participação de professores, linguistas aplicados, pesquisadores, líderes comunitários e, principalmente, autoridades do governo. $O$ processo de elaboração de uma política educacional eficaz consiste na fixação de uma série de objetivos, enunciados em termos concretos e práticos, que devem servir de guia para a ação imediata contendo mecanismos de avaliação (CHAGURI, 2010a).

A contribuição teórica, a seguir, nos permite fundamentar tal asserção que estamos apresentando:

As medidas concretas de como se atingir as metas devem estar claramente explicitadas. Além do mais, os objetivos devem ter relevância para os sujeitos envolvidos e devem ser colocados em escala de prioridades; por exemplo, garantir um ensino de qualidade em oposição a construir mais escolas. Para determinados políticos, a prioridade em relação à oposição citada como exemplo seria clara, uma vez que a escola construída, ou até em construção, tem maior visibilidade do que a qualidade do ensino, podendo, assim, carrear votos mais facilmente. (CELANI, 2000, p. 18)

Parece claro que as decisões sobre as questões de políticas educacionais não podem ser deixadas apenas nas mãos dos políticos, embora sejam eles, em última instância, os responsáveis legais pela fixação dessas políticas. É fundamental que as autoridades educacionais centrem seus objetivos e compactuem da mesma linguagem com a população em geral e comunidade acadêmica (GIMENEZ, 2005; CHAGURI, 2010a, 2010b), caso contrário, essa política não será capaz de tomar um corpo em si, garantindo ao aprendiz de uma LE a possibilidade da apropriação do conhecimento para a própria formação de seu espírito humano.

Segundo apresenta Amaral (2001), houve muitas discussões acerca da necessidade em possibilitar a oferta de uma LEC no setor público, nos anos iniciais do ensino

\footnotetext{
${ }^{6}$ Especialmente no âmbito no qual estamos enunciando nossa discussão - política de ensino-aprendizagem de LEC.
} 
fundamental durante a realização de dois encontros, - sendo o primeiro ${ }^{7}$ em 1996, e o segundo ${ }^{8}$ em 2000 -, acerca das especificidades das políticas de ensino de LE. Em ambos os eventos, discutiu-se entre os professores, pesquisadores e autoridades presentes, a possibilidade de viabilizar a oferta de uma LEC, bem como, os aspectos de ensinoaprendizagem de uma LEC do ensino fundamental.

Dentre essas diversas discussões e questionamentos levantados durante o I e II Enple $^{9}$, dos diversos aspectos que dificultam o ensino-aprendizagem de LEC estão a falta de documentos, as diretrizes e/ou parâmetros oficiais que venham oferecer encaminhamentos legais e metodológicos, de forma específica, para a condução de um estudo de uma LEC (PIRES, 2001; FIGUEIRA, 2002; TONELLI, 2005; TONELLI; CRISTOVÃO, 2010; RINALDI, 2006). A falta de uma orientação metodológica, como também, de uma orientação legal para o ensino-aprendizagem de LEC, pode refletir na formação de professores de LE. De acordo com diversos estudos de pesquisadores (VIEIRA-ABRHÃO, 2002; CELANI, 2002; TONELLI, 2008a; CHAGURI; TONELLI, 2010), a formação de professores de LE pode ser considerada também um dos problemas que agrava o processo de ensino-aprendizagem de LEC, além da falta de documentos para essa área.

Convergindo com Tonelli (2008a), Tonelli e Cristovão (2010) as pesquisadoras afirmam que a formação de professores de LE necessita de possíveis implicações em sua formação, por não tratar dos aspectos legais acerca das concepções presentes no processo de ensino-aprendizagem de LEC. Conforme as autoras, uma das problemáticas que se deve considerar como desafiadora no trabalho do professor de LEC é a ausência da formação de professores voltados para o ensino de LEC como foco de atenção dos cursos de licenciatura em Letras (TONELLI, 2008b; TONELLI; CRISTOVÃO, 2010), tornando a formação docente em muitos aspectos insuficiente.

Decorrente desse contexto, segundo Tonelli e Cristovão (2010), são os cursos de Pedagogia que oferecem formação sobre desenvolvimento infantil e aprendizagem, contudo, não oferecem formação em LE por não ser esse seu objetivo. Em contrapartida,

\footnotetext{
7 I Enple - Encontro Nacional sobre Política de Ensino de Línguas Estrangeiras, realizado na Florianópolis, Santa Catarina.

${ }^{8}$ II Enple - Encontro Nacional sobre Política de Ensino de Línguas Estrangeiras, realizado em Pelotas, Rio Grande do Sul.

${ }^{9}$ Encontro Nacional sobre Política de Ensino de Línguas Estrangeiras.
} 
os cursos de licenciatura em Letras se ocupam da formação de professores de línguas estrangeiras e materna, enfocando apenas teorias relacionadas ao ensino-aprendizagem de línguas para os alunos a partir do $6^{\circ}$ ano do ensino fundamental.

Mesmo havendo documentos e orientações educacionais legais, como diretrizes curriculares para os cursos de licenciatura, o que inclui o curso de Letras, referenciais e parâmetros (BRASIL, 1996, 1997) para vários níveis de ensino, o ensino de LE nos anos iniciais não está com seus propósitos e objetivos contemplados em tais documentos. A partir do corpus bibliográfico analisado fica evidente, portanto, que há uma necessidade de reformas no currículo dos cursos de licenciatura em Letras a fim de que sejam contemplados não só aspectos metodológicos, mas também políticos, pelos professores formadores das diversas instituições de ensino superior do país, e, claro, um foco a ser expandido também nas pesquisas em linguística aplicada.

Ao considerarmos a importância de se (re)pensar uma possível reformulação dos currículos do curso de Letras para que contemplem a formação de docentes de LEC, uma outra questão que se refere ao tema em foco, é o aspecto de cunho político que não está somente atrelado ao papel educacional da escola ao ofertar uma LEC, mas ao governo, que mesmo tendo a possibilidade de oferta de uma LEC, não o faz.

Verificamos, na Lei $n^{\circ}$ 9394/96, que as escolas básicas "poderão organizar-se classes, ou turmas, de níveis equivalentes de adiantamento na matéria, para o ensino de LE, artes, ou outros componentes curriculares" (BRASIL, 1996, p. 22, art. 24, inciso IV). Diante de tal afirmação, o governo pode, sim, criar condições que sejam possíveis para o estudo de uma LEC, e posteriormente, a escola deverá refletir sobre tais questões em relação à oferta da LEC, como a emancipação da LE como objetivo de conhecimento e domínio das construções de significados existentes na língua materna. Contudo, se legalmente existe a possibilidade de uma reorganização estrutural e curricular para o ensino-aprendizagem de LEC: por que o governo não possibilita às crianças dos anos iniciais do ensino fundamental o acesso ao estudo de uma LE?

Ao continuarmos a compor o caminho que este texto se preocupa em debater, sendo ele a presença ou não de uma política de ensino-aprendizagem a LEC, passaremos agora, a discutir as políticas públicas referentes ao ensino fundamental, para mais 
adiante, então, termos condições de enunciar uma resposta à problemática motivadora deste texto e a pergunta que acaba por se apresentar neste espaço enunciativo.

O governo, ao dar prioridade ao ensino fundamental em suas políticas públicas, quer possibilitar ao sistema educacional a superação dos problemas ligados ao ensino e à aprendizagem, sendo este o caminho mais indicado para uma erradicação do analfabetismo a médio e/ou longo prazo. Tais argumentos podem ser facilmente encontrados em discursos de governantes, educadores e até da sociedade civil que estão preocupados com os rumos da sociedade brasileira. Da união do governo com a sociedade civil surge a possibilidade do funcionamento das políticas públicas e do seu planejamento (CROCE, 2005). À sociedade cabe: "apoiar, fiscalizar, acompanhar e sugerir programas de âmbito nacional que possam priorizar a construção de um meio social menos excludente e mais justo" (CROCE, 2005, p. 35). Ao governo cabe: implementar programas voltados a todos para viabilizar o bem-estar coletivo por meio das decisões políticas.

Um aspecto de grande importância e que se deve ao fato de se tratar de assuntos de cunho político, é o entendimento do termo políticas públicas. No sentido de buscar esclarecimento desse termo, ecoamos o pressuposto de Höfling (2001), para quem as políticas públicas são compreendidas como o Estado em ação, ou seja, é o "Estado implantando um projeto de governo através de programas, de ações voltadas para setores específicos da sociedade" (HÖFLING, 2001, p. 31). Assim, o Estado não tem seu caráter reduzido a um processo burocrático público, que somente implementa uma ação de política pública; o Estado implementa uma política a partir de acordos decisórios em conjunto.

Nesse contexto, cabe aqui outra explicação conceitual. Trata-se de estabelecer a diferença entre política pública e decisão política. A política pública acontece a partir de uma decisão política que só é possível se houver interesses comuns entre políticos e sociedade civil, enquanto que a "[...] decisão política deve conferir àqueles que deverão executá-la, a adequação dos fins pretendidos aos meios disponíveis" (CROCE, 2005, p. 36). Convergindo com Höfling (2001) e Lück (2000), política pública implica em decisão política, ou seja, as ações que serão concretizadas no meio social podem ser afetadas em 
maior ou menor número. Isso tudo depende, sem dúvida, da decisão política imposta pelo governante.

Consoante às palavras de Chaguri (2010a), é a união entre governo e sociedade civil que poderá promover a sua efetivação. Por outro lado, segundo Croce (2005), elas estão vinculadas à ampliação e à manutenção de recursos materiais, humanos, econômicos e financeiros. A vontade política se manifesta a partir do momento em que os projetos sociais e educacionais são criados e, assim, colocados em prática, garantido os recursos necessários para sua existência no âmbito social.

Mediante o esclarecimento dessas questões (políticas públicas e decisão política), vemos que as possibilidades para a educação devem se orientar para uma democratização e ampliação das oportunidades educacionais. Os projetos que se voltam para o desenvolvimento social podem ser de base nacional ou serem orientados por organismos internacionais, tais como: Banco Mundial (BM); Fundo Monetário Internacional (FMI); Organização das Nações Unidas (ONU); Organização dos Estados Americanos (OEA) (CROCE, 2005).

Quando se trata da interferência de agentes internacionais, as decisões políticas ficam atreladas ao financiamento de programas para diferentes áreas sociais. Logo, políticas públicas e programas devem ser tratados nas suas especificidades, o que remete ao entendimento de que as políticas são pensadas e transformadas em lei, a fim de servir a todos os cidadãos e os programas visam ao atendimento de uma parcela específica da população. (CROCE, 2005, p. 36)

No caso da estruturação do ensino fundamental, o que se pode observar são políticas que determinam o alcance de recursos financeiros e materiais, mediante os programas específicos para captação desses recursos. Em um dos seus estudos, Fonseca (1998) esclarece os meios que esses agentes utilizam para controlar as tomadas de decisões das políticas internas. Além disso, Fonseca (2008) ainda afirma que esses agentes mantêm o controle das ações que cabem à educação por meio dos programas de apoio social.

Quando se trata de políticas públicas para a educação, são implementados no país diferentes tipos de programas e projetos sociais. O objetivo de tais programas e projetos 
sociais é ampliar e também manter o ensino fundamental em prioridade legal e política, sendo então, administrado de forma diferenciada, recebendo diversos incentivos. Um exemplo disso é a permanência do aluno na escola. No artigo 32 da Lei nº 9394/96 (BRASIL, 1996), é garantido aos estabelecimentos de ensino fundamental a adoção do sistema de ciclos e da progressão continuada.

Ancorando-nos nas palavras de Neubauer (2000) e Croce (2005), na proposta de progressão continuada, o autor deixa claro que se trata de uma mudança significativa nas relações entre a escola, a aprendizagem e o aluno, pois, o ensino fundamental do $1^{\circ}$ ao $5^{\circ}$ ano foi o responsável em introduzir o sistema de ciclos, dividindo-se em duas etapas as séries iniciais, e dando um novo aspecto à aprendizagem escolar. Dentro desse contexto, o aluno deixa de ser visto como um aprendiz incapaz e passa a ser visto como um aprendiz capaz de superar seus problemas de aprendizagem escolar.

Com o propósito de se buscar a qualidade no ensino fundamental, criou-se o Sistema Nacional de Avaliação da Escola Básica (SAEB). O intuito da criação desse programa é “[...] realizar um diagnóstico da educação básica brasileira e de alguns fatores que possam interferir no desempenho do estudante, fornecendo um indicativo sobre a qualidade do ensino ofertado" (BRASIL, 2015).

O SAEB foi aplicado pela primeira vez em 1990. Em 2005, foi reestruturado sendo composto por duas avaliações: Avaliação Nacional da Educação Básica (Aneb) e Avaliação Nacional do Rendimento Escolar (Anresc). Esta última é conhecida como Prova Brasil. Além disso, em 2013, foi incorporada ao SAEB a Avaliação Nacional da Alfabetização (ANA). Isso ocorreu para buscar uma melhoria nos níveis de alfabetização e letramento em Língua Portuguesa e no raciocínio lógico na Matemática.

As diretrizes elaboradas, a partir dessas considerações que enunciamos até o momento, constituem-se na afirmação do compromisso de governos e educadores com o desenvolvimento do país. Contudo, o que queremos chamar atenção, após o esclarecimento e discussão do que seja o termo políticas públicas, é o modo como está articulada essa política ao ensino fundamental. 


\section{neoliberalismo e a educação}

Assistimos hoje a uma transformação profunda no modo como é entendida e posta em prática a regulação das políticas educativas, no contexto de uma alteração mais ampla relacionada com a própria concepção, reforma e reestruturação do Estado e da sua administração.

De acordo com Paro (1999), fica perceptível um contínuo movimento de interação entre as decisões políticas nas diferentes esferas de gestão, mesmo havendo uma estrutura de relações de grandes complexidades. Conforme se estabelecem as palavras desse autor, a articulação nas negociações de âmbito político-institucional e econômicofinanceiras deve dar-se entre as partes dependentes, contudo, não subordinadas hierarquicamente.

A partir dos anos de 1980, houve o surgimento das chamadas políticas neoliberais. Trata-se da diminuição da ação do Estado em programas sociais para a população e a criação de mercados na esfera pública como educação, saúde e transporte. Essas políticas neoliberais afetaram diretamente não só o Brasil, mas também a América Latina e foram adotadas como referenciais para os programas de desenvolvimento conduzidos pelas grandes organizações internacionais (FMI, Banco Mundial etc.), no que foi designado pelo "Consenso de Washington" (BATISTA, 1994), cujas principais "receitas" passavam por: disciplina orçamental; reforma fiscal; eliminação das barreiras às trocas internacionais; privatização e desregulamentação, com o esquecimento da intervenção do Estado (BARROSO, 2005).

Com a entrada do século XXI, há um recuo das teorias mais radicais do neoliberalismo e a emergência de propostas alternativas que busquem o equilíbrio entre o “Estado" e o “mercado", (BARROSO 2003, 2005) ou mesmo no sentido de superar essa dicotomia pela reativação de formas de intervenção sócio-comunitária na gestão da esfera pública (BAROSSO, 2004).

Com o intuito de implementar as políticas públicas e viabilizar as decisões políticas para o ensino fundamental, o governo federal descentralizou administrativamente os órgãos federais para os Estados e Municípios (CROCE, 2005). Tal tarefa pode ser considerada como um ato extremamente político e analisada sob os aspectos não só 
político-social e legal como também, administrativo e pedagógico (BARROSO, 2005; OLIVEIRA 2006).

A descentralização do ensino inicia-se com a transferência de encargos e deveres do Governo Federal para os Estados e Municípios. Isso, então, acaba ocorrendo em diferentes níveis, envolvendo a estadualização de programas e projetos, e claro, a municipalização do ensino fundamental. Com isso, a unidade escolar passa a ter maior autonomia em suas decisões, mas, por outro lado, Ihe exigenovos papéis. Dessa forma, com a estratégia política de descentralização para o ensino fundamental, os municípios passam a ter responsabilidade no Plano Nacional de Alimentação Escolar (Merenda Escolar); e no Programa de Manutenção e Desenvolvimento do Ensino Fundamental (TV Escola, Programa de Apoio Tecnológico e Programa Dinheiro Direto na Escola) (CROCE, 2005). "Todos esses programas objetivam atender setores diferentes da vida escolar, além de possibilitar a permanência do aluno na escola" (CROCE, 2005, p. 41).

Vale destacar, ainda, que a escola passa a ter maior autonomia na ampliação das responsabilidades e decisões em suas unidades escolares. De acordo com as asserções de Fonseca (1998) e Paro (1999), o planejamento de parte do orçamento anual da escola como a prioridade de gastos e a elaboração do calendário escolar são apenas alguns dos exemplos dessas responsabilidades.

Contudo, apesar das escolas passarem a ter mais poder de decisões para resolver questões do cotidiano, a abertura da gestão escolar faz com que ela se envolva com a iniciativa privada, buscando, então, uma complementação orçamentária. Com isso, a contribuição da população passa ser importante para escola suprir suas necessidades de ordem financeira. Assim, no plano educacional brasileiro, a atual política educacional é descentralizada no financiamento e centralizada no controle, já que o "objetivo central não é adequar à educação e ao emprego, mas articular o mercado da educação com o mercado de emprego, nem que para isso seja necessário criar um mercado dos excluídos" (BARROSO, 2005, p. 742).

Com as informações e considerações até aqui apresentadas, pode-se inferir que, com a descentralização do Governo Federal para os Estados e Municípios em prol das decisões e implementações das políticas públicas para o ensino fundamental, vemos que a prioridade dada ao ensino fundamental é para superar problemas ligados ao ensino e à 
aprendizagem bem como, à erradicação do analfabetismo, sendo a médio e/ou em longo prazo. O que importa é manter a qualidade do ensino fundamental, conforme estabelecem "[...] as retóricas discursivas dos políticos, peritos e meios de informação" (BARROSO, 2005, p. 741), criando então, o processo de descentralização da educação.

Assim, diante do que já expomos, podemos, então, retomar uma reflexão já apresentada anteriormente neste artigo, e, a partir dela, elucidarmos novas reflexões. Desse modo, se existe o direito legal em possibilitar a oferta de uma LEC no setor público, conforme estabelece a Lei $n^{\circ}$ 9394/96 (BRASIL, 1996), por que as autoridades educacionais não propõem tal oferta?

Conforme discutido até o presente momento, e junto aos autores aqui arrolados, fica evidente que, caso o Estado e/ou os Municípios passem a ofertar o ensino de LEC como componente curricular, os mesmos terão que se reorganizar de forma política e econômica para atenderem essa nova demanda em seus estabelecimentos de ensino. Por conseguinte, isso gerará maiores gastos com a contratação de professores, materiais didáticos e capacitação continuada de profissionais, levando o Estado e/ou Município a buscarem alternativas e recursos orçamentários para darem conta dessa nova organização curricular, pedagógica, política e econômica em suas escolas.

Contudo, como já mencionado anteriormente, a prioridade do ensino fundamental é superar os problemas de aprendizagem e, assim, caminhar para uma possível erradicação do analfabetismo, e não para a construção de uma proposta educacional que se oriente para uma ação coletiva na área do ensino-aprendizagem de LEC (CHAGURI, 2010a), já que sua prioridade são as políticas públicas de corte social, balizado pelas políticas neoliberais.

Nessa mesma linha de preocupação, propomos a seguinte indagação: De que forma, então, pode ser criada uma política educacional para o ensino-aprendizagem de LEC, sem desconsiderar, a base do neoliberalismo educativo centrado por meio das políticas públicas no ensino fundamental?

Os estudos de Bohn (2000), Leffa (2001), Celani (2000), Gimenez (2005), Chaguri (2010a, 2010b), apresentam uma preocupação relacionada com a necessidade em se estabelecer uma política de ensino para LE. Tais autores chamam-nos atenção para o 
trabalho coletivo entre autoridades educacionais, sociedade civil e profissionais da educação ${ }^{10}$ na elaboração de uma política de ensino de línguas.

Como condição para a ação política, Bohn (2000, p. 128) afirma que "somente o somatório de forças pode construir a vontade coletiva necessária para a ação política." Neste caso, apesar de termos contribuições de estudos (SANTOS, 2002; FIGUEIRA, 2002; OLIVEIRA, 2003; SOUZA, 2005; CHAGURI, 2010a, 2010b) acerca de uma política de ensino de LE, ainda não há uma junção de forças ${ }^{11}$, para se estabelecer ações que pudessem orientar uma política de ensino de LE, e consequentemente, propor metas e objetivos para tal política, com o propósito de melhor orientar o ensino de LE nas instituições escolares, possibilitando, portanto, bases legais e pedagógicas (reformulação dos currículos do curso de Letras, por exemplo) para oferta de uma LEC nas séries iniciais do Ensino Fundamental.

Há alguns elementos que interferem na política de ensino de uma LE de um país e, por essa razão, é que ainda não se estabeleceu uma política de ensino de LE, e, por conseguinte, uma política de LEC.

a) Atores - autoridades educacionais, população acadêmica e (sociedade civil - na tentativa de se estabelecer um diálogo e objetivos que sejam concretos para um acordo com os legisladores).

b) Aspectos políticos "ideológicos" - finalidade política de uma LE, isto é, se requer o ensino de uma LE para certos objetivos políticoeconômico.

c) Aspectos estruturais - na e pela História compreende-se a oferta de uma LE no país e, de certa forma, mostrando os movimentos de centralização e descentralização de seu ensino; os períodos de ascensão e declínio da LE.

d) Conhecimento técnico - ser fluente no idioma significando ter uma boa formação técnica do professor.

e) Concepção de educação - o ensino de LE é atrelado a uma educação de instrumentalização ou emancipação do sujeito. Tais objetivos acordamse com os "aspectos estruturais" marcados na e pela História (CHAGURI, 2010a, p. 97). [grifos do autor]

\footnotetext{
${ }^{10}$ Neste texto, entendem-se como profissionais da educação professores de língua estrangeira, linguistas aplicados e especialistas das universidades.

${ }^{11}$ Somatório de forças como propõe Bohn (2000) junto à sociedade civil, professores e autoridades educacionais.
} 
Uma educação política na área do ensino de LE que esteja orientada para negociar acordos e compactuar de uma mesma linguagem, entre os atores (CHAGURI, 2010a) da política de ensino de LE, só ganhará um corpo em si, se a relação de poder (política) estiver direcionada para fins de formação humana, refutando, de modo veemente, a tendência atualmente presente no âmbito do Estado e de setores do ensino (políticas

neoliberais) que consiste em reduzir a gestão escolar a soluções estritamente tecnicistas, importadas da administração empresarial capitalista.

É preciso estar claro que ao se estabelecer uma política de ensino para LE e, assim o fazendo, possibilita-se então uma política de ensino-aprendizagem a LEC, e tal política não deve formar indivíduos para o mercado de trabalho ou para aprovações em testes e concursos ou simplesmente para atender às exigências de uma política educativa neoliberal (formação de mão de obra qualificada para inserção do país em um mercado capitalista). Ela (política de LE), em seu espaço (escola) e contexto (cultura) deve possibilitar a formação aos indivíduos para o desfrute de suas próprias vidas, ou seja, para viverem bem em meio aos bens criados pela humanidade.

Tendo clareza das relações de poder que queremos manter ou mudar, é que teremos então, uma possibilidade de viabilizar uma construção de política de ensino de LE em nosso país, e, posteriormente uma política de ensino-aprendizagem de LEC, promovendo, de certo modo, o acesso ao conhecimento de forma abrangente e dialética a fim de possibilitar a apreensão do real, a formação e possíveis nortes iniciais para a transformação da realidade.

\section{Considerações finais}

A relação de poder - política -, é que determina a escolha de uma língua a ser utilizada nas escolas de um determinado país, numa relação em que as palavras ganhem sua existência e se concretizem num contexto da enunciação. Dentro dessa perspectiva é que nos é possível perceber que a oferta de LE nas escolas de um determinado país não acontece sem haver conflitos na disputa de poder entre os países envolvidos no processo de aceitação para o ensino da LE. O momento de decisão pelo ensino de determinada LE é resultante de processo intenso de acordos e/ou imposições políticas, ideológicas e 
culturais. Neste ensejo, discutir, analisar e refletir sobre políticas de ensino de LE, principalmente para uma política específica para o ensino-aprendizagem de LEC gera sempre duas polêmicas: de um lado a necessidade em se buscar ações plausíveis para se estabelecer acordos e metas entre aqueles que configuram tal política para efetivação de um acordo comum entre as partes que compõem tal cenário; de outro, um governo contraditório porque descentraliza suas ações no financiamento, mas as centraliza no processo pedagógico, dificultando as discussões dos somatórios de força para o estabelecimento de uma LE conforme propõe Bohn (2000).

Com esse difícil caminho a ser trilhado parece impossível criar uma conexão entre o somatório de forças (BOHN, 2000) e o governo para se estabelecer uma política de ensino de LE que propicie a esta política a criação de novos significados por meio da nova língua que é a LE (ao se ter uma política de ensino), cujo ensino-aprendizagem possa ser determinado pela função social da LE em estudo em um momento histórico particular de um país.

Quando falamos em se propor ações políticas para o ensino de uma LE, é preciso esclarecer que ao se possibilitar o ensino de tal idioma como componente curricular obrigatório em um determinado país, e em nosso caso particular, a oferta de uma LEC, estamos tratando de uma concepção de língua enquanto discurso, enquanto espaço de produção de sentidos marcados por relações contextuais de poder (política), e não enquanto estrutura que intermediaria nosso contato com o mundo e por meio da qual os sentidos seriam transmitidos.

A língua, nesta concepção de discurso, constrói significados e não apenas os transmite. Por isso, propor a política de ensino-aprendizagem de uma LEC se faz importante para que possamos formar indivíduos que exerçam sua cidadania de forma ativa, crítica e, portanto, conscientes de sua capacidade de transformação da sociedade. 
ALMEIDA FILHO, José Carlos Paes. Por uma política de ensino de (outras) línguas. Revista Trabalhos em Linguística Aplicada. Campinas, v. 37, n. 1, p. 103-108, 2001.

AMARAL, Nívea Figueiredo. O ensino de línguas estrangeiras na formação integral das crianças: abordagem antroposófica. In: LEFFA, VilsonJosé. (Org.). 0 professor de línguas: construindo a profissão. Pelotas: Educat, 2001. p. 69-96.

BARROSO, João. "Escolha da escola" como processo de regulação: integração ou seleção social. In: BARROSO, João. (Org.). A escola pública: regulação, desregulação, privatização. Porto: ASA, 2003. p. 79-109.

BARROSO, João. Escola da Ponte: defender, debater e promover a escola pública. In: CANÁRIO, Rui; MATOS, Filomena; TRINDADE, Rui. (Orgs.). Escola da ponte: defender a escola pública. Porto: Profediçoes, 2004. p. 11-25.

BARROSO, João. O Estado, a educação e a regulação das políticas públicas. Rev. Educ. Soc., Campinas, v. 26, n. 92, p. 725-751, 2005.

BOHN, Hilário Inácio. Os aspectos 'políticos' de uma política de ensino de línguas e literaturas estrangeiras. Linguagem \& Ensino, Pelotas, v. 3, n. 1, p. 117-138, 2000.

BRASIL. Lei de Diretrizes e Bases da Educação. Lei nº 9.394 de 20 de novembro de 1996. Brasília, DF, [1996]

BRASIL. Ministério da Educação e Cultura. Parâmetros Curriculares Nacionais: introdução / ensino fundamental. Brasília, DF: MEC/SEF, 1997.

BRASIL. Ministério da Educação e Cultura. Saeb. Brasília: Mec/Inep, 2015. Disponível online em: http://portal.inep.gov.br/educacao-basica/saeb. Acesso em 12 jun. 2017.

BATISTA, Paulo Nogueira. 0 Consenso de Washington: a visão neoliberal dos problemas latino-americanos. São Paulo: Secretaria Operativa Consulta Popular, 1994. (Caderno $\mathrm{n}^{\circ} 7$ )

CELANI, Maria Antonieta Alba. A relevância da linguística aplicada na formulação de uma política educacional brasileira. In: FORTKAMP, Mailce Borges Mota; TOMITCH, Leda Maria Braga. (Orgs.). Aspectos da linguística aplicada: estudos em homenagem ao professor Hilário Inácio Bohn. Florianópolis: Insular. 2000. p. 17-32.

CELANI, MariaAntonietaAlba. Chuvinismo Linguístico: uma nova melodia para um velho tema? In: SILVA, Fábio Lopes da; RAJAGOPALAN, Kanavillil. (Orgs.). A Linguística que nos faz falhar. investigação crítica. São Paulo: Parábola, 2004. p. 119-124.

CELANI, Maria Antonieta Alba. Professores e formadores em mudança: relato de um processo de reflexão e transformação da prática docente. Campinas: Mercado de Letras, 2002. 
CELANI, Maria Antonieta Alba. English for al... preservando o forró. In: FIGUEIREDO, Célia Assunção; JESUS, Osvaldo Freitas de. Linguística aplicada: aspectos de leitura e do ensino de línguas. Uberlândia: Edufu, 2005. p. 13-25.

CHAGURI, Jonathas de Paula. As Vozes de uma política de ensino de língua estrangeira moderna na educação básica do Estado do Paraná. 2010a. 180 f. Dissertação (Mestrado em Educação) - Universidade Estadual de Maringá, Maringá, 2010.

CHAGURI, Jonathas de Paula. As vozes de uma política de ensino de língua estrangeira moderna na educação básica do Estado do Paraná. Revista Acta Scientiarum Education. Maringá, v. 32, n. 2, p. 225-236, 2010 b.

CHAGURI, Jonathas de Paula; TONELLI, Juliana Reichert Assunção. Alguns aspectos teóricos e políticos sobre a formação de professores de língua estrangeira. In: COLÓQUIO INTERNACIONAL DE ESTUDOS LINGUISTICOS E LITERARIOS - CIELLI, 1², 2010, Maringá, Anais [...] Maringá, 2010.

CROCE, Marta Lúcia. As políticas públicas para o ensino fundamental: uma introdução. In: AZEVEDO, Mario Luiz Neves de. (Org.). Política educacional brasileira. Maringá: Eduem, 2005. p. 33-50.

FIGUEIRA, Cristina. Crianças alfabetizadas aprendendo língua estrangeira. 2002.

Dissertação (Mestrado em Linguística Aplicada) - Universidade de Brasília, Brasília, 2002.

FONSECA, Marília. O Banco Mundial como referência para a justiça social no terceiro mundo: evidências do caso brasileiro. Rev. Fac. Educ. São Paulo, v. 24, n. 1, p. 37-69, 1998.

GIMENEZ, Telma Nunes. Políticas Governamentais, Mídias e o Ensino de Língua Estrangeira. In: GIMENEZ, Kilda, Maria Prado. Contribuições na área de línguas estrangeiras. Londrina: Moriá, 2005. p. 91-104,

HÖFLING Eloisa de Matos. Estado e políticas (públicas) sociais. Cadernos Cedes, Campinas, ano XXI, n. 54, nov., p. 30-41, 2001.

LEFFA, Vilson José. Aspectos políticos da formação do professor de línguas estrangeiras. In: LEFFA, Vilson José (Org.). O professor de línguas estrangeiras: construindo a profissão. Pelotas: Educat, 2001. p. 333-355.

LÜCK, Heloísa. Gestão escolar e formação de gestores. Brasília: Inep, 2000.

MOITA LOPES, Luis Paulo da. A nova ordem mundial, os parâmetros curriculares nacionais e o ensino de inglês no Brasil: a base intelectual para uma ação política. In: BARBARA, L; RAMOS, R. C. G. (Org.). Reflexão e ações no ensino-aprendizagem de línguas. Campinas: Mercado de Letras, 2003. p. 29-57. 
NEUBAUER, Rose. Quem tem medo da progressão continuada? ou melhor, a quem interessa o sistema de reprovação e exclusão social? 2000. Disponível online em http://www.apedu.org.br/site/2012/04/27/quem-tem-medo-da-progressao-continuada/. Acesso em 02 jun. 2018.

OLIVEIRA, Ramon de. Agências multilaterais e a educação profissional brasileira. Campinas: Editora Alínea, 2006.

OLIVEIRA, Ênio de. Políticas de Ensino de línguas estrangeiras em escolas públicas do Estado de São Paulo. 2003. 154 f. Dissertação (Mestrado em Linguística Aplicada) Universidade Estadual de Campinas, Instituto de Estudos da Linguagem, São Paulo, 2003.

PARO, Vitor Henrique. Parem de preparar para o trabalho! reflexões acerca dos efeitos do neoliberalismo sobre a gestão e o papel da escola básica. In: FERRETTI, Celso; et al; (Orgs). Trabalho, formação e currículo: para onde vai à escola. São Paulo, Xamã, 1999. p. 101-120.

PIRES, Simone Silva. Vantagens e desvantagens no ensino de língua estrangeira na educação infantil: um estudo de caso. 2001. $131 \mathrm{f}$. Dissertação (Mestrado em Estudos da Linguagem) - Universidade Federal do Rio Grande do Sul, Rio Grande do Sul, 2001.

RINALDI, Simone. Um relato da formação de professores de espanhol como língua estrangeira para crianças: um olhar sobre o passado, uma análise do presente e caminhos para o futuro. 2006. 177 f. Dissertação (Mestrado em Educação) - Faculdade de Educação, Universidade de São Paulo, São Paulo, 2006.

SANTOS, Katia Costa dos. Construção multicultural: reflexões sobre políticas alternativas para o ensino de língua estrangeira. 2002.171 f. Tese (Doutorado em Letras) - Faculdade de Filosofia Letras, e Ciências Humanas, Universidade de São Paulo, São Paulo, 2002.

SOUZA, Sérgio Augusto Freire de. 0 Movimento dos sentidos sobre línguas estrangeiras no Brasil: discurso, história e educação. 2005. 338 f. Tese (Doutorado em Linguística) Universidade Estadual de Campinas, Instituto de Estudos da Linguagem, São Paulo, 2005.

TONELLI, Juliana Reichert Assunção. Histórias infantis no ensino de língua inglesa para crianças. 2005. 359 f. Dissertação (Mestrado em Estudos da Linguagem) - Universidade Estadual de Londrina, Londrina, 2005.

TONELLI, Juliana Reichert Assunção. Novas propostas e novos desafios no ensino de línguas estrangeiras para crianças. In: CONGRESSO LATINO-AMERICANO DE FORMAÇÃO DE PROFESSORES DE LÍNGUAS - CLAFPL, II, 2008, Rio de Janeiro, Anais [...] Rio de Janeiro, 2008a.

TONELLI, Juliana Reichert Assunção. O uso de histórias infantis no ensino de inglês para crianças: analisando o gênero textual história infantil sob a perspectiva do interacionismo sociodiscursivo. Acta Scientiarum Language and Culture, Maringá, v. 30, n. 1, p. 19-27, 2008b. 
TONELLI, Juliana Reichert Assunção; CRISTOVÃO, Vera Lúcia Lopes. O Papel dos cursos de letras na formação de professores de inglês para crianças. Calidoscópio, São Leopoldo, v. $8, n^{\circ} 01$, p. 65-76, 2010.

VIEIRA-ABRAHÃO, Maria Helena. Teoria e Prática na Formação pré-serviço do professor de língua estrangeira. In: GIMENEZ, Telma Nunes. (Org.). Trajetórias na formação de professores de línguas. Londrina: Eduel, 2002. p. 59-76.

Recebido em: 12/06/2017

Revisões requeridas em: 18/12/2017

Aprovado em: 05/02/2018

Universidade do Estado de Santa Catarina - UDESC Programa de Pós-Graduação em Educação - PPGE

Revista Linhas

Volume 20 - Número 42 - Ano 2019

revistalinhas@gmail.com 